\title{
Enhanced Glycemic Control with Combination Therapy for Type 2 Diabetes in Primary Care
}

\author{
Louis Kuritzky · George P. Samraj
}

To view enhanced content go to www.diabetestherapy-open.com

Received: April 12, 2011 / Published online: August 1, 2011

(C) The Author(s) 2011. This article is published with open access at Springerlink.com

\begin{abstract}
Type 2 diabetes mellitus is an increasingly common medical problem for primary care clinicians to address. Treatment of diabetes has evolved from simple replacement of insulin (directly or through insulin secretagogs) through capture of mechanisms such as insulin sensitizers, alpha-glucosidase inhibitors, and incretins. Only very recently has recognition of the critical role of the gastrointestinal system as a major culprit in glucose dysregulation been established. Since glycated hemoglobin $A_{1 c}$ reductions provide meaningful risk reduction as well as improved quality of life, it is worthwhile to explore evolving paths for more efficient use of the currently available pharmacotherapies.
\end{abstract}

Louis Kuritzky $(\varangle) \cdot$ George P. Samraj

Department of Community Health and Family

Medicine, University of Florida College of Medicine,

Gainesville, Florida, FL 32605, USA.

Email: LKuritzky@aol.com

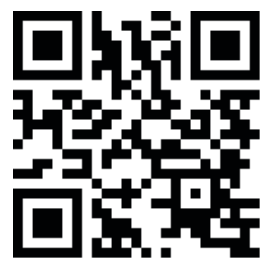

Enhanced content for this article is available on the journal web site: www.diabetestherapy-open.com
Because diabetes is a progressive disease, even transiently successful treatment will likely require augmentation as the disorder progresses. Pharmacotherapies with complementary mechanisms of action will be necessary to achieve glycemic goals. Hence, clinicians need to be well informed about the various noninsulin alternatives that have been shown to be successful in glycemic goal attainment. This article reviews the benefits of glucose control, the current status of diabetes control, pertinent pathophysiology, available pharmacological classes for combination, limitations of current therapies, and suggestions for appropriate combination therapies, including specific suggestions for thresholds at which different strategies might be most effectively utilized by primary care clinicians.

Keywords: DPP-4 inhibitor; exenatide; liraglutide; metformin; primary care; sitagliptin; thiazolidinedione; type 2 diabetes

\section{INTRODUCTION}

Globally, the World Health Organization (WHO) reports that as many as 220 million individuals have diabetes. ${ }^{1}$ The Framingham Offspring Study 
database indicates that the incidence of type 2 diabetes mellitus (DM2) has doubled in the US from the 1970s through the 1990s. ${ }^{2}$ In the US, it was estimated in 2010 that nearly 26 million individuals had diabetes, of which 7.0 million (27\%) were undiagnosed. ${ }^{3}$ Furthermore, the prevalence of diabetes (driven largely by DM2) is projected to reach $12.0 \%$ by 2050 , affecting more than 48 million individuals. ${ }^{4}$ Disconcertingly, almost half of deaths in this population occur before the age of 70 years, and the WHO projects that the number of diabetes deaths will double between 2005 and 2030. Clinicians also increasingly recognize the additional burden of DM2 in children and adolescents. ${ }^{5}$ Most patients with DM2 are appropriately managed within the primary care sector, with the occasional need for consultation by diabetologists.

Since DM2 is associated with increased mortality, increased risk of macrovascular disease (ie, stroke and myocardial infarction), and increased microvascular disease (ie, retinopathy, nephropathy, and neuropathy), there are numerous challenges worthy of intervention for risk reduction. Healthy diet, regular physical activity, maintaining a normal body weight, and avoiding tobacco use can prevent or delay the onset of diabetes.

Good control of glucose (glycated hemoglobin $\left.\mathrm{A}_{1 \mathrm{c}}\left[\mathrm{HbA}_{1 \mathrm{c}}\right]<7 \%\right)$ in patients with DM2 has been shown to reduce microvascular disease and improve quality of life. ${ }^{6}$ Despite the salutary effects attributable to good glucose control, only about half of patients with diabetes are at the currently recognized treatment goal. ${ }^{7}$ In addition to glycemic control, comprehensive DM2 care requires attention to blood pressure, lipids, and lifestyle factors (ie, diet, exercise, and abstinence from smoking), leading to complex medication and lifestyle treatment regimens. Failure to attain glycemic goals may reflect the competing demands of attaining multiple goals at the same time.
Currently, the most widely recognized measure for glycemic control is $\mathrm{HbA}_{1 \mathrm{c}}$, although exceptions, such as for persons with hemoglobinopathy, do exist. Recommendations from the American Diabetes Association (ADA) suggest an $\mathrm{HbA}_{1 \mathrm{c}}$ goal $<7.0 \% .{ }^{6}$ Ultimately, as diabetes progresses, most patients will require insulin therapy. However, the purpose of this communication is to focus upon ways primarily to capitalize on non-insulin combination therapies to achieve glycemic goals.

Guidelines from the European Association for the Study of Diabetes (EASD) concur with the concept that utilization of polypharmacy, especially early combination therapy, is one of the greatest advances in DM2 disease management. ${ }^{8}$ Skillful application of combination treatments will be necessary to attain and maintain adequate glucose control in the majority of DM2 patients. ${ }^{9}$ For diabetic patients who "deselect" injection therapy (ie, those who are unwilling or unable to use parenteral treatments), it will be particularly necessary to capitalize upon the complementary therapeutic effects of multiple oral agents.

\section{CONCERNS ABOUT THE CURRENT STATUS OF DIABETES CONTROL}

The current status of diabetes control is far from optimal. According to the most recent National Health and Nutrition Examination Survey (NHANES) data, between 2003 and 2006 only $57.1 \%$ of adults with diabetes surveyed had achieved the recommended $\mathrm{HbA}_{1 \mathrm{c}}$ target of $7.0 \%$ or lower. ${ }^{7}$ Other surveys have shown that $30 \%$ or more patients with diabetes have an $\mathrm{HbA}_{1 \mathrm{c}}$ greater than $8.0 \% .^{10,11}$ The complexity of multifaceted goal achievement is perhaps best reflected by 2003-2006 data from NHANES that showed the dismally low composite of only $12.2 \%$ of patients with diabetes achieving all 
three primary goals for $\mathrm{HbA}_{1 \mathrm{c}}(<7.0 \%)$, blood pressure $(<130 / 80 \mathrm{~mm} \mathrm{Hg})$, and low-density lipoprotein cholesterol $(<100 \mathrm{mg} / \mathrm{dL}){ }^{7}$

Additionally, despite consistent confirmation of treatment benefits, clinicians have been historically somewhat sluggish in advancement of pharmacotherapy to attain appropriate glucose goals. In a 2000-2002 study of 30 academic primary care and diabetes/ endocrinology clinics in the US, among patients with $\mathrm{HbA}_{1 \mathrm{c}}$ values above goal only $40.4 \%$ had their current treatment regimens adjusted at the most recent clinic visit. ${ }^{12}$ Similarly, a study from Kaiser Permanente (Northwest) data from 1994-2002 demonstrated that patients may not receive appropriate augmentation of therapy promptly: among patients on metformin monotherapy $(n=354)$, the average amount of time between their first $\mathrm{HbA}_{1 \mathrm{c}}$ reading $>8.0 \%$ and treatment augmentation or substitution was 14 months; for patients on sulfonylurea monotherapy ( $n=2517)$, the average duration was 20 months. ${ }^{13}$ Thus, there remains a great, unmet need for prompt and effective intensification of diabetes management. Early combination therapy offers promise in this regard.

Recognizing that many patients with DM2 languish for protracted periods with glucose levels well above the recognized toxic threshold, the most recent ADA/EASD algorithm has provided a pathway for more prompt control of hyperglycemia by indicating the propriety of introducing insulin as an early agent in combination therapy with metformin to achieve glucose management goals. ${ }^{14}$ We do not dispute the advantages of prompt control or the efficiency of goal attainment with insulin. Rather, we see great opportunity for improved recognition of the prompt glycemic control that can be attained with skillful combination of non-insulin therapies, and advancement of therapy with greater chronological alacrity.
Treatment advancement typically relies upon measurement of $\mathrm{HbA}_{1 \mathrm{c}}$. Although long-term management is appropriately directed by $\mathrm{HbA}_{1 \mathrm{c}}$, initial management, rapid advancement of pharmacotherapy requires monitoring of fasting glucose status, which can reflect day-today changes in control, versus the 90-120-day control window provided by $\mathrm{A}_{1 \mathrm{c}}$ monitoring. As discussed below, most currently available agents achieve as much as $80 \%$ or more of their potential to lower fasting glucose within 4 weeks of initiation. Waiting to advance therapy beyond that interval suggests lack of awareness of the time course of action of therapy.

Additionally, Monnier et al. ${ }^{15}$ (Figure 1) have shown that in most newly diagnosed patients with DM2 (particularly when $\mathrm{HbA}_{1 \mathrm{c}}$

Figure 1. Relative contributions of postprandial and fasting hyperglycemia (\%) to the overall diurnal hyperglycemia over quintiles of glycated hemoglobin $A_{1 C}$ $\left(\mathrm{HbA}_{1 \mathrm{c}}\right) .{ }^{15}$ Adapted with permission from Diabetes Care 2003;26:881-885. Reproduced with permission from the American Diabetes Association. a=Significant difference was observed between fasting and postprandial plasma glucose (paired $t$ test). $b=$ Significantly different from all other quintiles (analysis of variance [ANOVA]). $\mathrm{c}=$ Significantly different from quintile 5 (ANOVA).

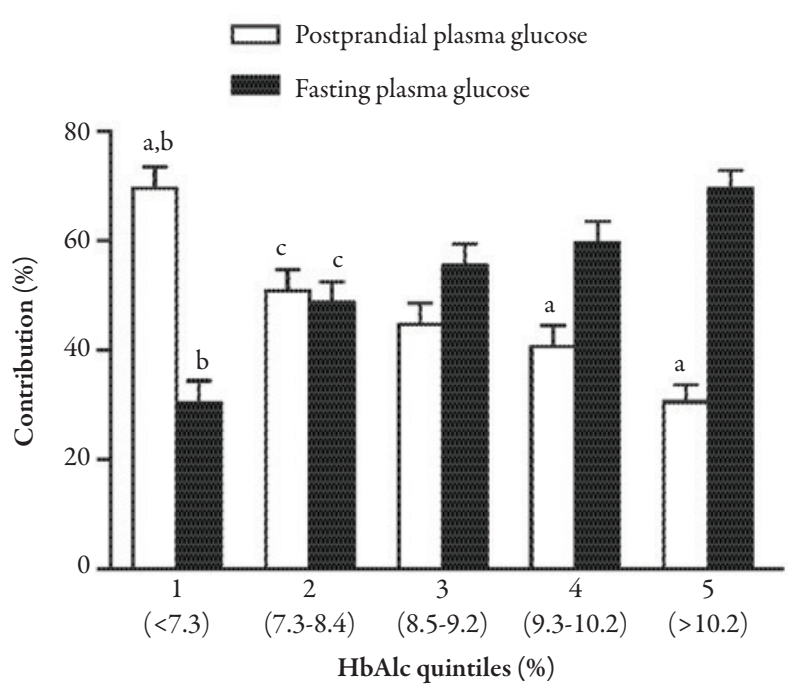


is $>7.3 \%$ ), it is the fasting glucose component of dysglycemia that is the primary contributor to elevated $\mathrm{HbA}_{1 \mathrm{c}}$. Hence, we believe in a "fix the fasting first" philosophy when addressing most individuals with hyperglycemia. Although there is a linear relationship between $\mathrm{HbA}_{1 \mathrm{c}}$ and adverse outcomes, recent literature (notably from the Action to Control Cardiovascular Risk in Diabetes ${ }^{16}$ [ACCORD] study) has challenged the concept that lower is always better. In ACCORD, patients randomized to tight control $\left(\mathrm{HbA}_{1 \mathrm{c}}<6.0 \%\right)$ had worse cardiovascular outcomes than those randomized to "traditional" therapy. ${ }^{16}$ The ADA 2011 position statement reiterates that $\mathrm{HbA}_{1 \mathrm{c}}$ goals must be individualized. ${ }^{17}$ Considerations for individualization include age, health status, comorbidities, regimen complexity, body habitus, economic issues, duration of diabetes, presence of known cardiovascular disease, microvascular complications, hypoglycemia awareness, and personal health preferences. ${ }^{17}$

Indeed, there are some circumstances where prudence would argue against tight control. For instance, persons with a history of severe hypoglycemia may be at risk for further recurrences. If a patient has hypoglycemia unawareness, glucose levels may progress to precariously low levels before characteristic symptoms emerge to stimulate correction, placing the patient at substantial risk. Similarly, medications that mask or blunt physiological responses to hypoglycemia (eg, beta-blockers and alpha-beta-blockers) may augment risk. In any of these circumstances, clinicians would be wise to avoid overly tight control.

\section{BENEFITS OF GLYCEMIC CONTROL}

In the UK Prospective Diabetes Study (UKPDS), ${ }^{33}$ the composite endpoint of "any diabetesrelated endpoint" was reduced by $12 \%$ for an achieved $\mathrm{HbA}_{1 \mathrm{c}}$ of $7.0 \%$ (intensive treatment group) versus $7.9 \%$ (conventional treatment group), microvascular endpoints (retinopathy, nephropathy, neuropathy) were reduced by $25 \%$, and there was also a decrease in need for laser treatments and cataract surgery. ${ }^{18}$ These beneficial effects were seen without distinction as to which category of pharmacotherapy was used; that is, no demonstrable difference in endpoint reduction among sulfonylurea, insulin, or metformin was noted in the overall population studied. In addition to microvascular treatment benefits seen in UKPDS, long-term observation of the cohort showed what has been termed the "legacy effect": favorable effects years after conclusion of the trial. After 10 years of post-trial monitoring, the group that had received intensive treatment originally showed reductions in any diabetes-related endpoint, microvascular disease, myocardial infarction, and all-cause mortality; these favorable results were found despite the fact that by the end of this observation period, $\mathrm{HbA}_{1 \mathrm{c}}$ levels in the group originally assigned to intensive treatment were essentially the same as the group originally assigned to conventional treatment. ${ }^{19}$ Another important trial that showed benefits of glucose control in DM2 was the Kumamoto study. ${ }^{20}$ In a population of 110 Japanese DM2 patients, retinopathy was reduced by $69 \%$ and nephropathy by $70 \%$ after 6 years of intensive glucose control to an $\mathrm{HbA}_{1 \mathrm{c}}$ level of $7.1 \% .^{20}$

One of the often neglected benefits of good glucose control is the effect upon quality of life. Although motivation for patients to adhere to medication regimens may spring from a desire to avoid microvascular and macrovascular consequences, patients who feel better are directly rewarded for their efforts. In a randomized, double-blind study of DM2 patients $(n=569)$, subjects were assigned to active treatment (sulfonylurea) or placebo for 
12 weeks, at which point numerous quality of life endpoints were compared. ${ }^{21}$ Symptom distress, general perceived health, cognitive functioning, and overall visual analog scale improved in the treatment group, but worsened in the placebo group. Active treatment also had an impact on the number of work days missed. In their zeal to prevent "hard" endpoints, clinicians should not lose sight of the benefits on quality of life that may be achieved through good glucose control.

\section{RELEVANT PATHOPHYSIOLOGY}

DM2 is a progressive disorder; it appears that once beta-cell loss begins, the process continues indefinitely. ${ }^{22}$ We know of no therapy that has been shown to meaningfully attenuate this progressive loss in humans. The progressive nature of diabetes necessitates that clinicians become familiar with complementary therapies that are necessary as the disease progresses.

DM2 is considered an "ecogenic" disorder, meaning that both genetic and lifestyle factors are involved. Pathogenic defects involved in glucose dysregulation include the pancreas (alpha and beta cells), the gastrointestinal tract, liver, skeletal muscle, and adipose tissue. Stressors, such as infection or injury, that activate counter-regulatory hormones (cortisone and epinephrine) may also contribute to glucose dysregulation (see ADA Position Statement ${ }^{23}$ ).

Multiple pathologies are associated with diabetes, foremost of which (at least initially), appears to be insulin resistance. ${ }^{24}$ As much as a decade before fasting or postprandial glucose becomes elevated (Figure 2), insulin resistance may be present. As long as increased beta-cell activity compensates for this insulin resistance, no derangement of fasting or postprandial glucose is evident.

It has been reported that by the time a diagnosis of DM2 has been made, $50 \%$ of beta-cell function has been lost. ${ }^{26}$ At this point, insufficient insulin is available to counteract insulin resistance, and suprathreshold glucose levels (postprandial and/or fasting) emerge. It is obvious that diabetic dysfunction occurs well before we make the clinical diagnosis, because as many as $50 \%$ of DM2 patients already have one or more diabetic complications the day the diagnosis is made. ${ }^{27}$

Insulin resistance occurs in multiple tissue compartments: the skeletal muscle, liver, and adipose compartment all exhibit insulin resistance leading to both hyperglycemia and dyslipidemia. It is not surprising, therefore, that multiple therapies will be needed to address multiple pathophysiological defects. For instance, the gastrointestinal tract is increasingly recognized as a critical organ in glucose metabolism. The incretin class of agents, currently comprising the glucagon-like peptide-1 (GLP-1) receptor agonists, such as exenatide and liraglutide, and dipeptidyl peptidase-4 (DPP-4) inhibitors, such as sitagliptin,

Figure 2. Natural history of type 2 diabetes. Upper panel: the dotted line represents the threshold for diagnosing impaired fasting glucose (IFG; $110 \mathrm{mg} / \mathrm{dL}$ ). Lower panel: the dotted line represents a reduction in relative function by about $50 \% .{ }^{25}$ Figure adapted with permission from Natural History of Type 2 Diabetes $@ 2010$ International Diabetes Center, Minneapolis, MN, USA.

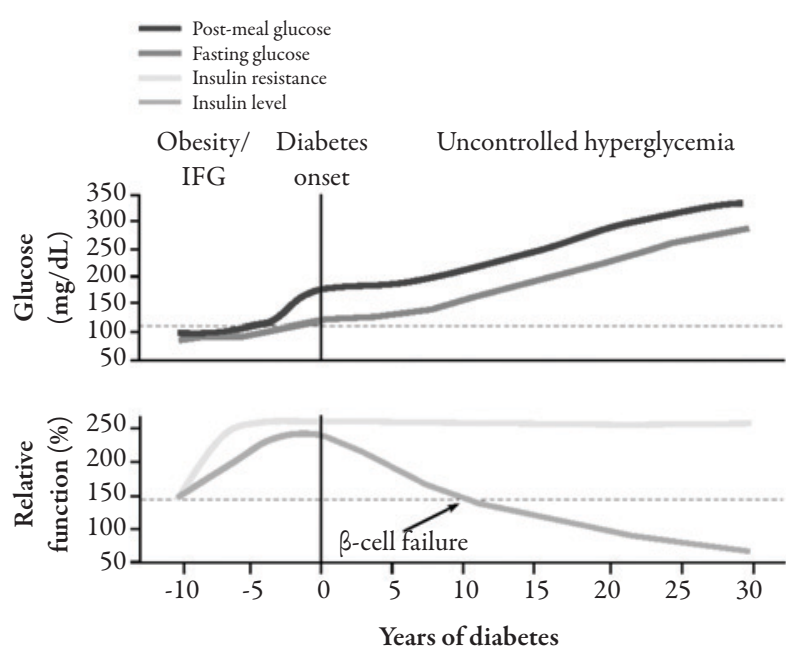


saxagliptin, and linagliptin, harnesses the capacity of GLP-1 to modulate glucose. Indeed, it has been suggested that more than $50 \%$ of mealstimulated insulin production is attributable to intestinal incretins. ${ }^{28}$

Another gastrointestinal-related phenomenon in diabetes is the absence of first-phase insulin secretion. ${ }^{29}$ In healthy individuals, a dietary glucose load is met with an almost immediate insulin response known as first-phase insulin release; this prompt response by preformed insulin keeps pace with rapidly rising glycemia. Due to the absence of first-phase insulin release (typical of DM2), rapidly rising glucose levels are unmet and result in inappropriate tissue exposure to elevated glucose. Alpha-glucosidase inhibitors help to address this pathophysiological defect by slowing glucose absorption, incretins do so by delaying gastric emptying, and a low glycemic index diet addresses this defect by selecting foods that produce a less rapid rise in glucose levels.

Pancreatic alpha-cell dysfunction compounds the problems of hyperglycemia. Supranormal glucose levels in healthy individuals suppress glucagon production by alpha cells, yet diabetic patients demonstrate continued glucagon production, even in the presence of hyperglycemia. In response to hyperglycemia, rising insulin levels should shut down hepatic glycogenolysis. However, since the liver is also insulin resistant, it does not respond appropriately to insulin levels, and continues to produce glucose despite hyperglycemia. Incretins suppress excess glucagon production. Although insulin resistance is the pathological defect with which clinicians are most familiar, it should be clear from the discussion above that incretin pathways, particularly as related to glucagon dysregulation, also offer an opportunity for modulation of a fundamental pathophysiological defect in DM2.

\section{PHARMACOLOGICAL CATEGORIES}

Many therapeutic choices exist, which allows individualized intervention by selecting medications that work in a complementary fashion to address the various pathophysiological defects of DM2. Currently available antidiabetic medications are broadly classified into four mechanistic groups: insulin enhancers, insulin sensitizers, hepatic modulators, and intestinal

Table 1. Mechanisms of action of commonly used antidiabetic medications. ${ }^{14}$

\begin{tabular}{|c|c|c|c|c|}
\hline Drugs & $\begin{array}{l}\text { Increased } \\
\text { insulin }\end{array}$ & $\begin{array}{l}\text { Insulin } \\
\text { resistance }\end{array}$ & $\begin{array}{l}\text { Hepatic glucose } \\
\text { metabolism }\end{array}$ & $\begin{array}{c}\text { Intestinal glucose } \\
\text { absorption/regulation }\end{array}$ \\
\hline $\begin{array}{l}\text { Alpha-glucosidase } \\
\text { inhibitors }\end{array}$ & & & & $\mathrm{X}$ \\
\hline Metformin & & $\mathrm{X}$ & $\mathrm{X}$ & \\
\hline Sulfonylureas & $\mathrm{X}$ & & & \\
\hline Glinides & $\mathrm{X}$ & & & \\
\hline Thiazolidinediones & & $\mathrm{X}$ & $\mathrm{X}$ & \\
\hline GLP-1 R analogs & $\mathrm{X}$ & & $\mathrm{X}$ & $\mathrm{X}$ \\
\hline DPP-4 inhibitors & $\mathrm{X}$ & & $\mathrm{X}$ & $\mathrm{X}$ \\
\hline
\end{tabular}

DPP-4=dipeptidyl peptidase-4; GLP-1 R=glucagon-like peptide-4 receptor. 
regulators (Table 1). Combination therapies should employ agents with complementary mechanisms. There is no suggestion that using two agents with similar mechanisms (eg, sulfonylurea plus a glinide) will be beneficial.

\section{Tolerability}

Any choice of therapy should, of course, include considerations of tolerability. The most common factors that limit acceptability are weight gain and hypoglycemia. To ensure adherence and success in goal attainment, clinicians should routinely advance therapy in a method that minimizes risk of hypoglycemia, as well as providing clear advice about management of hypoglycemia, should it occur. Finally, consistent enquiry about medication-induced adverse effects that might limit compliance should be routine.

\section{MANAGEMENT OF DIABETES}

Pharmacotherapy for dysglycemia is only one limb of the treatment approach. All persons with DM2 will require lifestyle changes, periodic monitoring of cardiovascular risk factors (lipids, glucose, and blood pressure), attention to target-organ damage (renal-function, ophthalmological-function, and nerve-function monitoring), and a long-term relationship with healthcare professionals; therefore, we do not wish to oversimplify care of diabetes to just glucose control. That being said, skillful control of glucose is a cornerstone of comprehensive therapy. Unfortunately, monotherapy has distinct limitations for most patients.

\section{Limitations of Current Monotherapies}

Monotherapy is unlikely to maintain adequate control in DM2 over the long term. This does
Figure 3. Median glycated hemoglobin $\mathrm{A}_{1 \mathrm{C}}\left(\mathrm{Hb}_{\mathrm{lc}}\right)$ levels in cohorts of patients followed up to 10 years by assigned treatment in the UK Prospective Diabetes Study (UKPDS) $34 . .^{30}$ Figure adapted with permission from DeFronzo et al., Annals of Internal Medicine; 1999. Table inset from Turner et al. ${ }^{31}$

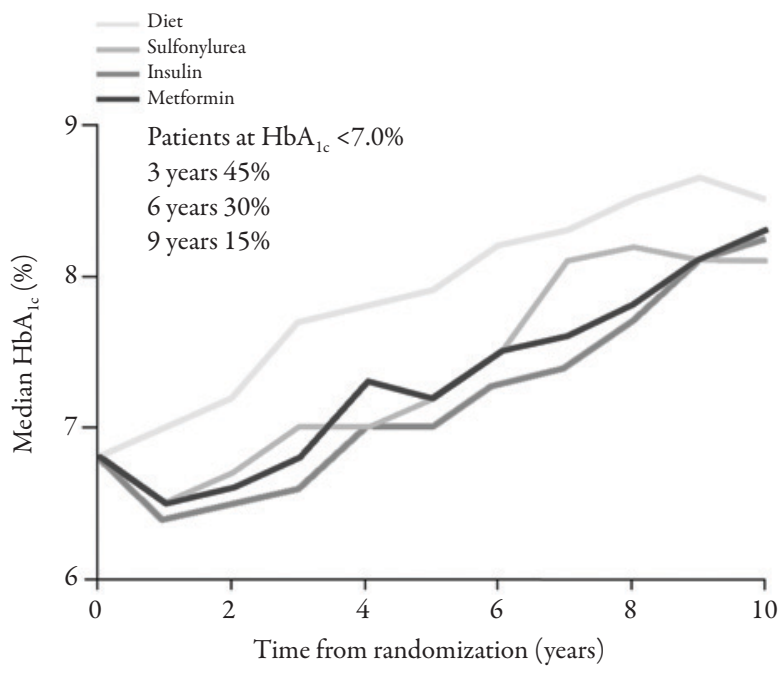

not necessarily reflect inadequacy of the pharmacotherapy, but instead may reflect several other factors. First, DM2 is a progressive disease and no treatment has been convincingly shown to retard this loss of function. As can be seen in Figure 3, all four treatment choices in the UKPDS (diet, metformin, sulfonylurea, and insulin) were associated with progressive loss of $\mathrm{HbA}_{1 \mathrm{c}}$ control despite titration. ${ }^{32}$ After 3 years on treatment, only $45 \%$ of patients remained at target $\mathrm{HbA}_{1 \mathrm{c}}$, and by 6 years, only 30\% of those receiving monotherapy were at goal. ${ }^{31}$ Hence, clinicians must become aware of the essential inevitability of polypharmacy for glucose control in patients with DM2. Second, many persons become more sedentary as they age because of the combined effects of social phenomena, comorbidities such as osteoarthritis, and some diabetes-induced disabilities (eg, diabetic peripheral neuropathic pain). Third, common comorbidities, such as hypertension, may be treated with medications that worsen glucose control (eg, diuretics and beta-blockers). Finally, patient "fatigue" (less 
enthusiasm over long periods of time) may foster poor adherence.

There are limited data to inform clinicians about durability of monotherapy. The A Diabetes Outcome Progression Trial ${ }^{9}$ (ADOPT) compared long-term monotherapy with rosiglitazone, metformin, or glyburide in recently diagnosed DM2 patients $(n=4360)$ with reference to their ability to maintain a fasting glucose $<180 \mathrm{mg} / \mathrm{dL}$. At 5 years, the rosiglitazone group failure rate (15\%) was lower than the sulfonylurea (34\%) and metformin (21\%) treatment groups. This is the only long-term treatment trial of its type, but lends credence, along with the UKPDS, to the concept that monotherapy is not sustainable in the majority of patients over the long term.

One of the inherent limitations of any monotherapy (except insulin) is that there is a ceiling, or maximum, potential effect on $\mathrm{HbA}_{1 \mathrm{c}}$. Mean reductions in $\mathrm{HbA}_{1 \mathrm{c}}$ with any monotherapy are rarely greater than $2.0 \%$
( $0.5 \%$ to $1.5 \%)$, depending upon the agent and initial $\mathrm{HbA}_{1 \mathrm{c}}$ level (Table 2). ${ }^{33}$ Hence, monotherapy for a patient who is newly diagnosed with DM2 and presents with an $\mathrm{HbA}_{1 \mathrm{c}}>9.0 \%$ is unlikely to attain an $\mathrm{HbA}_{1 \mathrm{c}}$ goal $<7.0 \%$; as the presenting $\mathrm{HbA}_{1 \mathrm{c}}$ increases further, $\mathrm{HbA}_{1 \mathrm{c}}$ goal attainment becomes progressively less likely.

\section{Combination Therapy}

At the current time, an agent of any one of the classes of pharmacotherapy may be rationally combined with any other. Exceptions include combining glinides (nateglinide, repaglinide) with sulfonylureas, which both work by essentially identical methods, so their combination would not be rational (no greater effect would be anticipated). Similarly, use of two agents from the incretin class (GLP-1 receptor analogs and DPP-4 inhibitors) would not be complementary, and would not be

Table 2. Comparison of clinical profiles of common antidiabetic medications.

\begin{tabular}{|c|c|c|c|c|c|}
\hline \multirow[b]{2}{*}{ Drug } & \multirow{2}{*}{$\begin{array}{l}\text { Mean } \mathrm{HbA}_{1 \mathrm{c}} \\
\text { reduction }\end{array}$} & \multicolumn{2}{|c|}{$\begin{array}{l}\text { Time to achieve maximum } \\
\text { therapeutic benefit, weeks }\end{array}$} & \multirow[b]{2}{*}{ Limitations } & \multirow{2}{*}{$\begin{array}{c}\text { Common adverse } \\
\text { events }\end{array}$} \\
\hline & & $>80 \%$ & $100 \%$ & & \\
\hline Metformin & $1.0 \%$ to $2.0 \%$ & 4 & $<9$ & $\begin{array}{l}\text { Renal failure, } \\
\text { CHF }\end{array}$ & GI side effects \\
\hline $\begin{array}{l}\text { Sulfonylurea (eg, glipizide } \\
\text { GITS) }\end{array}$ & $1.0 \%$ to $2.0 \%$ & Approximately 6 & Approximately 8 & Renal, hepatic & Hypoglycemia \\
\hline Glinide (eg, nateglinide) & $1.0 \%$ to $2.0 \%$ & Approximately 3 & 4 & $\begin{array}{l}\text { Three or four times } \\
\text { a day dosing }\end{array}$ & Hypoglycemia \\
\hline Alpha-glucosidase inhibitor & $0.5 \%$ to $0.8 \%$ & - & - & None & GI side effects \\
\hline $\begin{array}{l}\text { Thiazolidinedione (eg, } \\
\text { pioglitazone) }\end{array}$ & $0.5 \%$ to $1.0 \%$ & 6 & 14 & $\begin{array}{l}\text { Severe CHF, } \\
\text { weight gain }\end{array}$ & Weight gain \\
\hline DPP-4 inhibitors & $0.5 \%$ to $0.8 \%$ & 3 & 6 & Renal disease & \\
\hline Exenatide & $1.0 \%$ to $2.0 \%$ & 3 & 4 & Renal disease & Nausea \\
\hline Liraglutide & $0.5 \%$ to $1.1 \%$ & 2 & 4 & - & \\
\hline
\end{tabular}

$\mathrm{CHF}=$ chronic heart failure; DPP-4=dipeptidyl peptidase-4; GI=gastrointestinal; GITS=gastrointestinal therapeutic system. Based on Kuritzky et al. ${ }^{33}$ 
Figure 4. Suggested treatment algorithm for patients with type 2 diabetes mellitus, according to glycated hemoglobin $\mathrm{A}_{1 \mathrm{C}}\left(\mathrm{HbA}_{1 \mathrm{c}}\right)$ level at presentation. Treatment should be adjusted every 4 weeks (6-8 weeks for thiazolidinediones [TZDs]) based upon degree of fasting blood glucose (FBG) attained. ${ }^{14}$ Adjust dosage $\mathrm{q} 4 \mathrm{w}^{*}$ based upon degree of FBG reduction attained.

${ }^{*} \mathrm{q} 6-8 \mathrm{w}$ for TZDs.

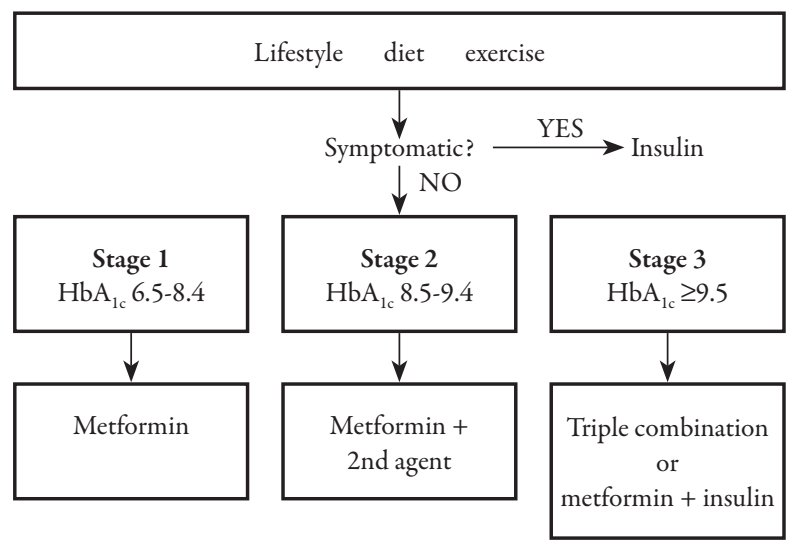

expected to have an enhanced effect. Although disputed by some, the preponderance of expert opinion suggests that the combination of any insulin secretagogue with insulin is not rational polypharmacy. ${ }^{14}$ With those exceptions, agents from any other classes may be successfully combined. Choice of therapeutic agent should be influenced by the level of $\mathrm{HbA}_{1 \mathrm{c}}$ elevation. For simplification purposes pertinent to the majority of patients seen in the primary care setting, we stratify diabetic control by $\mathrm{HbA}_{1 \mathrm{c}}$ level: stage 1 $\left(\mathrm{HbA}_{1 \mathrm{c}} 6.5 \%\right.$ to $\left.8.4 \%\right)$, stage $2\left(\mathrm{HbA}_{1 \mathrm{c}} 8.5 \%\right.$ to $9.4 \%)$, and stage $3\left(\mathrm{HbA}_{1 \mathrm{c}}>9.5 \%\right)$ (Figure 4$)$. This approach is based on the concepts explored by Nathan et al. in the ADA/EASD consensus statement. ${ }^{14}$

Lifestyle is at the foundation of all treatment regimens and may alone reduce $\mathrm{HbA}_{1 \mathrm{c}}$ as much as $2.9 \%$. This potential efficacy notwithstanding, the majority of patients with lifestyle modification will still require adjunctive monotherapy to control $\mathrm{HbA}_{1 \mathrm{c}}$ even at stage 1 ; unless a specific contraindication exists, metformin should be a therapeutic component at all steps of treatment. At stage 2, we believe it is unlikely that $\mathrm{HbA}_{1 \mathrm{c}}$ will be sufficiently controlled with monotherapy (metformin), so combination therapy should be considered routinely. With metformin as the foundation, a second agent (at lowest dose) may be initiated concomitantly, titrating the dose as often as every 4 weeks. As Table 2 shows, $80 \%$ or more of drug efficacy is measurable within that interval (with the exception of thiazolidinediones, which may require 6-8 weeks to attain a similar magnitude of efficacy). ${ }^{35,36}$ In a meta-analysis of randomized controlled trials of at least 3 months duration evaluating the addition of non-insulin antidiabetic drugs to maximal stable metformin therapy, all classes of agent were associated with similar significant reductions in $\mathrm{HbA}_{1 \mathrm{c}}$ versus placebo and were significantly more likely to achieve $\mathrm{HbA}_{1 \mathrm{c}}$ goal than placebo (Table 3). ${ }^{37}$

We disagree with the most recent American Association of Clinical Endocrinologists (AACE) guideline that suggests combination therapy as the initial step for persons with $\mathrm{HbA}_{1 \mathrm{c}} 7.0 \%$ to $8.0 \%,{ }^{38}$ noting that a substantial component of this population (especially those at the lower end of this range) will be able to attain goal with one of the more potent agents; a similar approach (initial monotherapy with metformin, for instance) is supported in the most recent ADA/EASD position paper. ${ }^{14}$ Utilization of polypharmacy prior to maximizing glycemic control with well chosen monotherapy seems, to us, overtreatment at stage 1 and exposes the patient to unnecessary expense, potential adverse effect profile, complexity, and risk for hypoglycemia.

Stage $2 \mathrm{HbA}_{1 \mathrm{c}}$ levels can occasionally be controlled with monotherapy, but most 
Table 3. Results of a meta-analysis of randomized controlled trials comparing the efficacy of noninsulin antidiabetic drugs when added to metformin therapy in patients with type 2 diabetes not controlled by metformin alone. Adapted with permission from Phung et al. JAMA 2010;303:1410-1418. ${ }^{37}$ Copyright (C) 2010 American Medical Association. All rights reserved.

\begin{tabular}{lcccc}
\hline & \multicolumn{2}{c}{ Percentage change in $\mathrm{HbA}_{1 \mathrm{c}}$} & \multicolumn{2}{c}{ HbA $_{1 \mathrm{c}}$ goal achieved } \\
\cline { 2 - 5 } Group vs. placebo & No. of trials & WMD $(\mathbf{9 5 \%}$ CI $)$ & $\begin{array}{c}\text { No. of } \\
\text { trials }\end{array}$ & RR $(95 \%$ CI $)$ \\
\hline All drugs & 20 & $-0.79(-0.90,-0.68)^{*}$ & 10 & $2.56(1.99,3.28) \dagger$ \\
Sulfonylureas & 3 & $-0.79(-1.15,-0.43)^{*}$ & 1 & $3.38(2.02,5.83)$ \\
Glinides & 2 & $-0.71(-1.24,-0.18)$ & 1 & $3.20(1.47,7.58)$ \\
Thiazolidinediones & 3 & $-1.00(-1.62,-0.38) \dagger$ & 1 & $1.69(1.24,2.33)$ \\
AGIs & 2 & $-0.65(-1.11,-0.19)$ & 0 & $\mathrm{NA}$ \\
DPP-4 inhibitors & 8 & $-0.79(-0.94,-0.63) \dagger$ & 6 & $2.44(1.78,3.33) \dagger$ \\
GLP-1 analogs & 2 & $-0.99(-1.19,-0.78)$ & 1 & $3.96(2.37,6.79)$ \\
\hline
\end{tabular}

${ }^{*}{ }^{2} \geq 75 \%$

$+P^{2}=50 \%$ to $75 \%$

AGIs= $\alpha$-glucosidase inhibitors; DPP-4=dipeptidyl peptidase-4; GLP-1=glucagon-like peptide-1; $\mathrm{Hb}_{1 \mathrm{c}}=$ hemoglobin $\mathrm{A}_{1 \mathrm{c}}$; $\mathrm{NA}=$ not applicable; $\mathrm{RR}=$ relative risk; $\mathrm{WMD}=$ weighted mean difference.

individuals at stage 2, and essentially all persons at stage 3 , merit initiation of combination therapy at the outset, since no monotherapy (insulin excepted) has a significant likelihood of attaining its goal. ${ }^{39,40}$ Indeed, at stage 3 it is likely that triple therapy will be necessary, although occasionally, metformin combined with fully titrated insulin may achieve its goal. ${ }^{41}$ For symptomatic patients at any stage of diabetes or during acute metabolic stress (eg, infection or surgery), consideration of insulin to correct the typical large excursions of glucose is appropriate. Often, after a period of stabilization in these patients, a return to oral therapy may be more convenient. As mentioned above, patient preferences should also ultimately shape the therapeutic plan.

The ADA/EASD algorithm for the metabolic management of DM2 (Figure 5) supports initial treatment of DM2 with metformin, in the absence of contraindications. ${ }^{14}$ All other classes of pharmacotherapy are complementary to metformin. Choice of the next agent will largely depend upon the above-mentioned factors, because there is a paucity of well controlled clinical trials that directly compare different diabetes treatment regimens. ${ }^{14}$ As mentioned earlier, a recent meta-analysis of antidiabetic agents combined with metformin demonstrated similar $\mathrm{HbA}_{1 \mathrm{c}}$ reductions with all classes of agents, but differences in their associations with weight gain and risk of hypoglycemia. ${ }^{37}$ The combination with which clinicians have the most familiarity is probably metformin plus a sulfonylurea. The use of this combination is reflected in a 29-week study ${ }^{42}$ comparing monotherapy with glyburide or metformin versus glyburide plus metformin. The results showed the combination provided near maximal reduction in fasting glucose within 5 weeks, amounting to an $80-\mathrm{mg} / \mathrm{dL}$ greater reduction than either monotherapy. ${ }^{42} \mathrm{~A}$ longer-term study, the PRESERVE-Beta trial, ${ }^{43}$ assessed the effects of glyburide or nateglinide plus metformin 
in 428 treatment-naïve patients with DM2 over 2 years. In patients treated with glyburide/ metformin, $\mathrm{HbA}_{1 \mathrm{c}}$ was reduced from $8.3 \%$ to $6.9 \%$ after 104 weeks, whereas nateglinide/ metformin treatment reduced $\mathrm{HbA}_{1 \mathrm{c}}$ from $8.4 \%$ to $6.9 \%$ ( $P<0.0001$ vs. baseline for both groups), demonstrating that good glycemic control can be maintained for 2 years with either treatment regimen. ${ }^{43}$
In a 6-month study of DM2 patients ( $n=701$ ) whose baseline $\mathrm{HbA}_{1 \mathrm{c}}$ was $8.0 \%$ while on metformin (ie, the preferred initial oral monotherapy in DM2 as per the 2009 ADA/ EASD algorithm ${ }^{14}$ ), subjects were randomized to placebo or sitagliptin $100 \mathrm{mg}$ once daily. ${ }^{44}$ By the end of the trial, mean $\mathrm{HbA}_{1 \mathrm{c}}$ was $7.26 \%$ in the DPP-4 inhibitor group versus $7.95 \%$ in the placebo group. Another study evaluating

Figure 5. American Diabetes Association and the European Association for the Study of Diabetes (ADA/EASD) consensus algorithm for the metabolic management of type 2 diabetes. Reinforce lifestyle interventions at every visit and check glycated hemoglobin $\mathrm{A}_{\mathrm{lc}}\left(\mathrm{HbA}_{1 \mathrm{c}}\right)$ every 3 months until $\mathrm{HbA}_{1 \mathrm{c}}$ is $<7 \%$ and then at least every 6 months. The interventions should be changed if $\mathrm{HbA}_{1 \mathrm{c}}$ is $\geq 7 \%{ }^{14}$ a Sulfonylureas other than glibenclamide (glyburide) or chlorpropamide. ${ }^{b}$ Insufficient clinical use to be confident regarding safety. $\mathrm{CHF}=$ congestive heart failure; GLP-1=glucagon-like peptide-1. Copyright 2009 American Diabetes Association. From Diabetes Care 2009;32:193-203. Reproduced with permission from the American Diabetes Association.

Tier 1: Well-validated core therapies

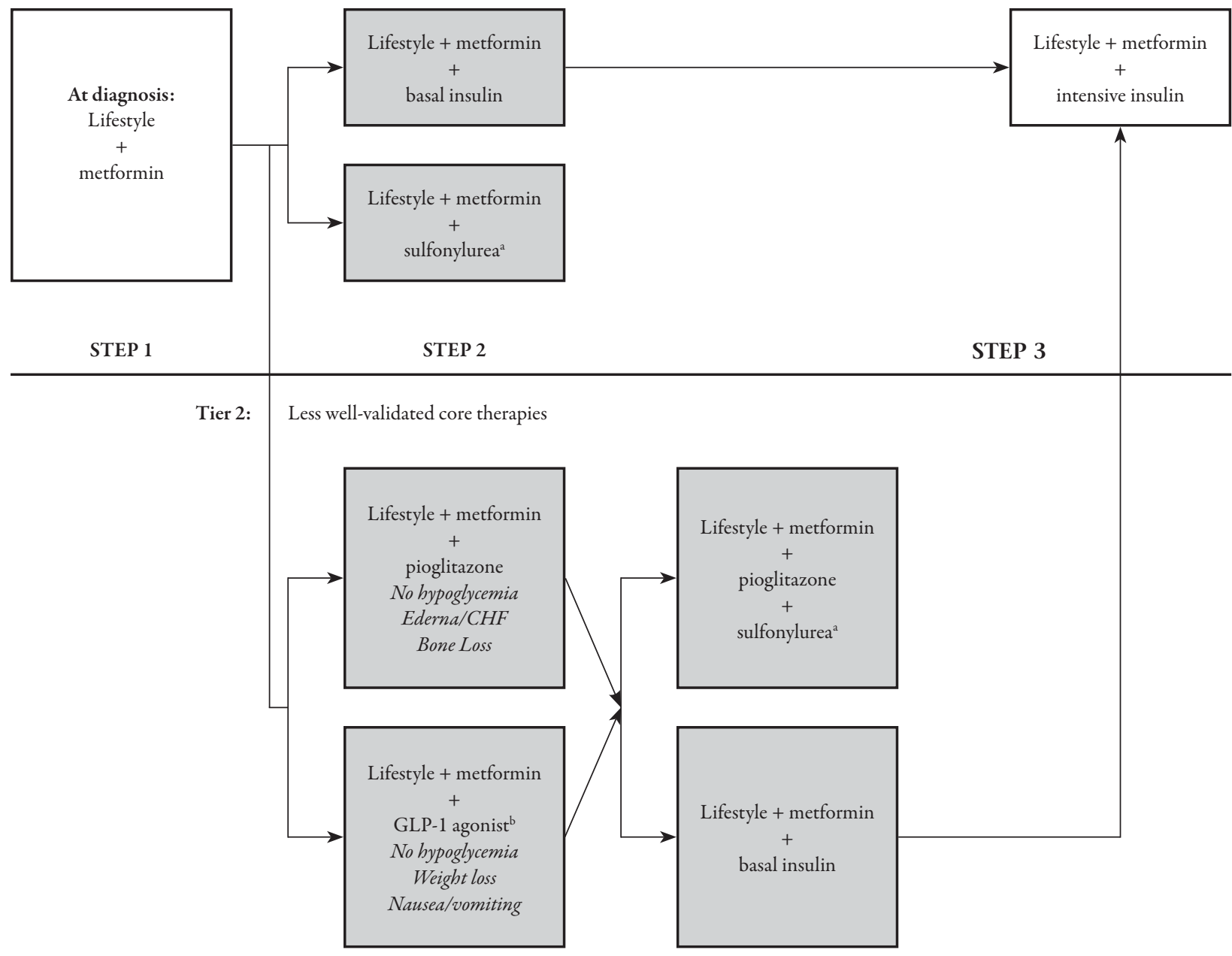


a combination of metformin plus a DPP-4 inhibitor assessed sitagliptin (100 mg once daily or $50 \mathrm{mg}$ twice daily) and metformin (500 or $1000 \mathrm{mg}$ twice daily) alone and in combination in 1091 DM2 patients with mean baseline $\mathrm{HbA}_{1 \mathrm{c}} 8.8 \% .{ }^{45}$ Adding sitagliptin $50 \mathrm{mg}$ twice daily to metformin $500 \mathrm{mg}$ twice daily provided another $0.6 \% \mathrm{HbA}_{1 \mathrm{c}}$ reduction compared with metformin alone. Similarly, adding sitagliptin $50 \mathrm{mg}$ twice daily to metformin $1000 \mathrm{mg}$ twice daily provided an additional $0.8 \% \mathrm{HbA}_{1 \mathrm{c}}$ reduction compared with metformin alone. Two 52-week studies assessed the efficacy and safety of two other DPP-4 inhibitors, vildagliptin ${ }^{46}$ and saxagliptin, ${ }^{47}$ in patients with DM2 inadequately controlled with metformin. Results of these trials demonstrated that addition of a DPP-4 inhibitor to a metformin regimen resulted in $\mathrm{HbA}_{1 \mathrm{c}}$ reductions comparable to those with glicazide plus metformin ${ }^{46}$ or glipizide plus metformin,${ }^{47}$ with the added advantage of fewer hypoglycemic events, and either weight loss or no weight gain. Thus, the currently available DPP-4 inhibitors have more in common with each other than dissimilarities between them. Efficacy of $\mathrm{HbA}_{1 \mathrm{c}}$ reduction, safety, and tolerability appear comparable for the three currently available DPP-4 inhibitors. A Canadian trial conducted in 16 clinics assembled 200 DM2 patients with $\mathrm{HbA}_{1 \mathrm{c}} \geq 8.5 \%$ despite being on maximally tolerated doses of metformin and a sulfonylurea (mean baseline $\mathrm{HbA}_{1 \mathrm{c}}$ was 9.7\%). ${ }^{41}$ The ADA/ EASD 2009 algorithm identifies metformin plus a sulfonylurea as a well validated steptwo combination. ${ }^{14}$ It is not uncommon for clinicians to choose oral triple-therapy combinations, despite the lack of support that a third oral agent could bring patients from so high an $\mathrm{HbA}_{1 \mathrm{c}}$ (9.7\%) down to goal $(<7.0 \%)$. Indeed, at the end of the trial, only $14 \%$ of subjects who had a thiazolidinedione (troglitazone) added to their existing sulfonylurea/metformin regimen achieved an $\mathrm{HbA}_{1 \mathrm{c}}<7.0 \%$. $^{41}$

This communication has focused primarily upon skillful combinations of non-insulin tools. Nonetheless, sometimes, insulin is a preferred choice, especially when combination therapy is likely to consist of three or more agents or when patients are symptomatic. Rather than trying to achieve control with three oral agents, earlier addition of basal insulin (ie, neutral protamine hagedorn [NPH], detemir, or glargine) or incretin mimetic (exenatide, liraglutide) is much more likely to attain an $\mathrm{HbA}_{1 \mathrm{c}}$ goal $<7.0 \%$. The Treatto-Target Trial $^{48}$ compared insulin glargine and NPH administered once nightly in 756 DM2 subjects with an $\mathrm{HbA}_{1 \mathrm{c}}>7.5 \%$ who were receiving one or two oral agents. After 18 weeks, the mean $\mathrm{HbA}_{1 \mathrm{c}}$ in both groups had dropped to $7.0 \%$. The frequency of hypoglycemia was significantly greater in the group that received NPH, but both agents were equally successful in reaching the $\mathrm{HbA}_{1 \mathrm{c}}$ goal $(<7.0 \%)$.

The DURATION-2 trial, ${ }^{49}$ a 26 -week doubleblind randomized study, assessed the efficacy and safety of exenatide once weekly $(n=170)$ versus sitagliptin $(n=172)$ or pioglitazone $(n=172)$ in metformin-treated patients. At the end of the study, $\mathrm{HbA}_{1 \mathrm{c}}$ levels were reduced significantly more by exenatide $(7.2 \%)$ than with sitagliptin $(7.7 \%)$ or pioglitazone $(7.4 \%)$; treatment differences were -0.6 for exenatide versus sitagliptin $(P<0.0001)$ and -0.3 for exenatide versus pioglitazone $(P=0.0165)$. Also, in a double-blind, placebo-controlled study in 733 patients treated with metformin and a sulfonylurea, exenatide-treated patients were more likely to achieve $\mathrm{HbA}_{1 \mathrm{c}}$ levels $\leq 7 \%$ than placebo-treated subjects (exenatide $10 \mu \mathrm{g}, 34 \%$ and $5 \mu \mathrm{g}, 27 \%$, placebo, 9\%; both doses of exenatide $P<0.0001) .{ }^{50}$ Liraglutide, the latest GLP-1 agonist to come to the US 
market, was evaluated in a series of phase 3 trials (Liraglutide Effect and Action in Diabetes [LEAD]); ${ }^{51-54}$ liraglutide therapy resulted in an average $\mathrm{HbA}_{1 \mathrm{c}}$ level reduction of $1.18 \%$ across all trials.

\section{CONCLUSIONS}

Skillful management of DM2 requires attention to multiple paths of dysfunction, with particular regard for lifestyle modulation, glucose control, cardiovascular risk factor reduction, and respect for the complexity such a diverse disorder places before our patients. Microvascular toxicity (retinopathy, nephropathy, and neuropathy) is reduced by good glucose control; hence, prompt glycemic goal attainment should be a compelling agenda. Combination therapy is an appropriate tool to maximize success in glucose control. Historically, sluggishness to advance treatment in a timely fashion despite inadequate goal attainment (commonly called "clinical inertia"), contributed to by both clinicians and patients alike, has been commonplace in DM2 patients. The plentiful and diverse tools available for good glucose control allow rational combinations to promptly gain control of dysglycemia. Lack of awareness of the timecourse of action of therapeutic agents may have limited the briskness with which clinicians titrate dosage. We hope that the instructive tables and diagrams depicting the typical timecourse of efficacy for available agents will be instrumental in addressing previous obstacles to prompt goal attainment. Consistent goal attainment can be enhanced by awareness of the pertinent physiological derangements attendant to DM2. Skillful combination of pharmacotherapies is intended to reduce risk for target organ damage and improve the quality of our patients' lives.

\section{ACKNOWLEDGMENTS}

This work was supported by Boehringer Ingelheim Pharmaceuticals, Inc (BIPI). Editorial assistance was provided by Elaine Griffin, MA, DPhil, of Envision Scientific Solutions, which was contracted by BIPI for these services. The authors meet the criteria for authorship as recommended by the International Committee of Medical Journal Editors (ICMJE), were fully responsible for all content and editorial decisions, and were involved at all stages of manuscript development. The authors received no compensation related to the development of the manuscript. Dr Kuritzky is the guarantor for this article, and takes responsibility for the integrity of the work as a whole.

Open Access. This article is distributed under the terms of the Creative Commons Attribution Noncommercial License, which permits any noncommercial use, distribution, and reproduction in any medium, provided the original author(s) and source are credited.

\section{REFERENCES}

1. World Health Organization (WHO). Fact sheet No 312: diabetes. Available at: www.who.int/ mediacentre/factsheets/fs312/en/index.html. Accessed February 11, 2011.

2. Fox CS, Pencina MJ, Meigs JB, Vasan RS, Levitzky YS, D'Agostino RBS. Trends in the incidence of type 2 diabetes mellitus from the 1970s to the 1990s: the Framingham Heart Study. Circulation. 2006;113:2914-2918.

3. National Diabetes Information Clearinghouse. National Diabetes Statistics, 2011. Available at: http://diabetes.niddk.nih.gov/dm/pubs/statistics/. Accessed February 11, 2011.

4. Narayan KM, Boyle JP, Geiss LS, Saaddine JB, Thompson TJ. Impact of recent increase in incidence on future diabetes burden: U.S., 20052050. Diabetes Care. 2006;29:2114-2116.

5. American Diabetes Association (ADA). Type 2 diabetes in children and adolescents. Diabetes Care. 2000;23:381-389. 
6. American Diabetes Association (ADA). Standards of medical care in diabetes--2010. Diabetes Care. 2010;33(Suppl. 1):S11-61.

7. Cheung BM, Ong KL, Cherny SS, Sham PC, Tso AW, Lam KS. Diabetes prevalence and therapeutic target achievement in the United States, 1999 to 2006. Am J Med. 2009;122:443-453.

8. Rydén L, Standl E, Bartnik M, van den Berghe G, Betteridge J, de Boer MJ, et al. Guidelines on diabetes, pre-diabetes, and cardiovascular diseases: executive summary. The Task Force on Diabetes and Cardiovascular Diseases of the European Society of Cardiology (ESC) and of the European Association for the Study of Diabetes (EASD). Eur Heart J. 2007;28:88-136.

9. Kahn SE, Haffner SM, Heise MA, Herman WH, Holman RR, Jones NP, et al. Glycemic durability of rosiglitazone, metformin, or glyburide monotherapy. N Engl J Med. 2006;355:2427-2443.

10. Resnick HE, Foster GL, Bardsley J, Ratner RE. Achievement of American Diabetes Association clinical practice recommendations among US adults with diabetes, 1999-2002: the National Health and Nutrition Examination survey. Diabetes Care. 2006;29:531-537.

11. Saadddine JB, Engelgau MM, Beckles GL, Gregg EE, Thompson TJ, Narayan KM. A diabetes report card for the United States: quality of care in the 1990s. Ann Intern Med. 2002;136:565-574.

12. Grant RW, Buse JB, Meigs JB. Quality of diabetes care in the US academic medical centers: low rates of medical regimen change. Diabetes Care. $2005 ; 28: 337-442$.

13. Brown JB, Nichols GA. Glycemic burden of oral agent failure in type 2 diabetes. Diabetes. 2003;52(Suppl. 1):A62. Abstract 264-260R.

14. Nathan DM, Buse JB, Davidson MB, Ferrannini E, Holman RR, Sherwin R, et al. Medical management of hyperglycemia in type 2 diabetes: a consensus algorithm for the initiation and adjustment of therapy: a consensus statement of the American Diabetes Association and the European Association for the Study of Diabetes. Diabetes Care. 2009;32:193-203.

15. Monnier L, Lapinski H, Colette C. Contributions of fasting and postprandial plasma glucose increments to the overall diurnal hyperglycemia of type 2 diabetic patients: variations with increasing levels of $\mathrm{HbA}(1 \mathrm{c})$. Diabetes Care. 2003;26:881-885.
16. Gerstein HC, Miller ME, Byington RP, Goff DCJ, Bigger JT, Buse JB, et al. Effects of intensive glucose lowering in type 2 diabetes. $\mathrm{N}$ Engl J Med. 2008;358:2545-2559.

17. American Diabetes Association (ADA). Standards of medical care in diabetes-2011. Diabetes Care. 2011;34(Suppl. 1):S11-S61.

18. UK Prospective Diabetes Study (UKPDS) Group. Intensive blood-glucose control with sulphonylureas or insulin compared with conventional treatment and risk of complications in patients with type 2 diabetes (UKPDS 33). Lancet. 1998;352:837-853.

19. Holman RR, Paul SK, Bethel MA, Matthews DR, Neil HA. 10-Year follow-up of intensive glucose control in type 2 diabetes. N Engl J Med. 2008;359:1577-1589.

20. Ohkubo Y, Kishikawa H, Araki E, Miyata T, Isami $\mathrm{S}$, Motoyoshi $\mathrm{S}$, et al. Intensive insulin therapy prevents the progression of diabetic microvascular complications in Japanese patients with noninsulin-dependent diabetes mellitus: a randomized prospective 6-year study. Diabetes Res Clin Pract. 1995;28:103-117.

21. Testa MA, Simonson DC. Health economic benefits and quality of life during improved glycemic control in patients with type 2 diabetes mellitus: a randomized, controlled, double-blind trial. JAMA. 1998;280:1490-1496.

22. Wajchenberg BL. beta-cell failure in diabetes and preservation by clinical treatment. Endocr Rev. 2007;28:187-218.

23. Kitabchi AE, Umpierrez GE, Murphy MB, Barrett E, J., Kreisberg RA, Malone JI, et al. Hyperglycemic crises in diabetes. Diabetes Care. 2004;27 (Suppl. 1):94-102.

24. Surampudi PN, John-Kalarickal J, Fonseca VA. Emerging concepts in the pathophysiology of type 2 diabetes mellitus. Mt Sinai J Med. 2009;76:216-226.

25. International Diabetes Center. Natural History of Type 2 Diabetes $^{\odot}$ 2010. Available at: www.cme. umn.edu/prod/groups/med/@pub/@med/@cme/ documents/content/med_content_188835.pdf.

26. Matthews DR, Cull CA, Stratton IM, Holman RR, Turner RC. UKPDS 26: Sulphonylurea failure in non-insulin-dependent diabetic patients over six years. UK Prospective Diabetes Study (UKPDS) Group. Diabet Med. 1998;15:297-303. 
27. UK Prospective Diabetes Study (UKPDS). VIII. Study design, progress and performance. Diabetologia. 1991;34:877-890.

28. Freeman JS. Role of the incretin pathway in the pathogenesis of type 2 diabetes mellitus. Cleve Clin J Med. 2009;76(Suppl. 5):S12-S19.

29. Del Prato S, Tiengo A. The importance of firstphase insulin secretion: implications for the therapy of type 2 diabetes mellitus. Diabetes Metab Res Rev. 2001;17:164-174.

30. DeFronzo RA. Pharmacologic therapy for type 2 diabetes mellitus. Ann Intern Med. 1999;131:281303.

31. Turner RC, Cull CA, Frighi V, Holman RR. Glycemic control with diet, sulfonylurea, metformin, or insulin in patients with type 2 diabetes mellitus: progressive requirement for multiple therapies (UKPDS 49). UK Prospective Diabetes Study (UKPDS) Group. JAMA. 1999;281:2005-2012.

32. UK Prospective Diabetes Study (UKPDS) Group. Effect of intensive blood-glucose control with metformin on complications in overweight patients with type 2 diabetes (UKPDS 34). Lancet. 1998;352:854-865.

33. Kuritzky L, Epstein BJ, Lavernia F. How to obtain appropriate type 2 diabetes control in the first 180 days of treatment initiation. Postgrad Med. 2010;122:33-42.

34. ADA Clinical Practice Recommendations. Diabetes Care. 2010;33(Suppl. 1): S1-S100.

35. Aronoff S, Rosenblatt S, Braithwaite S, Egan JW, Mathisen AL, Schneider RL. Pioglitazone hydrochloride monotherapy improves glycemic control in the treatment of patients with type 2 diabetes: a 6-month randomized placebo-controlled dose-response study. The Pioglitazone 001 Study Group. Diabetes Care. 2000;23:1605-1611.

36. Lebovitz HE, Dole JF, Patwardhan R, Rappaport EB, Freed MI. Rosiglitazone monotherapy is effective in patients with type 2 diabetes. J Clin Endocrinol Metab. 2001;86:280-288.

37. Phung OJ, Scholle JM, Talwar M, Coleman CI. Effect of noninsulin antidiabetic drugs added to metformin therapy on glycemic control, weight gain, and hypoglycemia in type 2 diabetes. JAMA. 2010;303:1410-1418.

38. American Association of Clinical Endocrinologists (AACE) Diabetes Clinical Practice Guidelines
Task Force. American Association of Clinical Endocrinologists medical guidelines for clinical practice for the management of diabetes melllitus. Endocr Pract. 2007;13(Suppl. 1):1-68.

39. Drucker DJ, Sherman SI, GOrelick FS, Bergenstal RM, Sherwin RS, Buse JB. Incretin-based therapies for the treatment of type 2 diabetes: evaluation of the risks and benefits. Diabetes Care. 2010;33:428-433.

40. Elasy TA, Levy P, Davis SN. Optimizing combination therapy for type 2 diabetes in adolescents and adults: a case-based approach. J Fam Pract. 2004;53:815-822.

41. Yale JF, Valiquett TR, Gjazzi MN, Owens-Grillo JK, Whitcomb RW, Foyt HL. The effect of a thiazolidinedione drug, troglitazone, on glycemia in patients with type 2 diabetes mellitus poorly controlled with sulfonylurea and metformin. A multicenter, randomized, double-blind, placebocontrolled trial. Ann Intern Med. 2001;134 (9 Pt 1):737-745.

42. DeFronzo RA, Goodman AM, The Multicenter Metformin Study Group. Efficacy of metformin in patients with non-insulin-dependent diabetes mellitus. N Engl J Med. 1995;333:541-549.

43. Gerich J, Raskin P, Jean-Louis L, Purkayastha D, Baron MA. PRESERVE-beta: two-year efficacy and safety of initial combination therapy with nateglinide or glyburide plus metformin. Diabetes Care. 2005;28:2093-2099.

44. Charbonnel B, Karasik A, Liu J, Wu M, Meininger G. Efficacy and safety of the dipeptidyl peptidase- 4 inhibitor sitagliptin added to ongoing metformin therapy in patients with type 2 diabetes inadequately controlled with metformin alone. Diabetes Care. 2006;30:2638-2643.

45. Goldstein BJ, Feinglos MN, Lunceford JK, Johnson J, Williams-Herman DE. Effect of initial combination therapy with sitagliptin, a dipeptidyl peptidase- 4 inhibitor, and metformin on glycemic control in patients with type 2 diabetes. Diabetes Care. 2007;30:1979-1987.

46. Filozof C, Gautier JF. A comparison of efficacy and safety of vildagliptin and gliclazide in combination with metformin in patients with Type 2 diabetes inadequately controlled with metformin alone: a 52-week, randomized study. Diabet Med. 2010;27:318-326.

47. Goke B, Gallwitz B, Eriksson J, Hellqvist A, Gause-Nilsson I. Saxagliptin is non-inferior to glipizide in patients with type 2 diabetes mellitus 
inadequately controlled on metformin alone: a 52week randomised controlled trial. Int J Clin Pract. 2010;64:1619-1631.

48. Riddle MC, Rosenstock J, Gerich J. The Treat-toTarget trial: randomized addition of glargine or human NPH insulin to oral therapy of type 2 diabetic patients. Diabetes Care. 2003;26:3080-3086.

49. Bergenstal RM, Wysham C, Macconell L, Malloy J, Walsh B, Yan P, et al. Efficacy and safety of exenatide once weekly versus sitagliptin or pioglitazone as an adjunct to metformin for treatment of type 2 diabetes (DURATION-2): a randomised trial. Lancet. 2010;376:431-439.

50. Kendall DM, Riddle MC, Rosenstock J, Zhuang D, Kim DD, Fineman MS, et al. Effects of exenatide (exendin-4) on glycemic control over 30 weeks in patients with type 2 diabetes treated with metformin and a sulfonylurea. Diabetes Care. 2005;28:1083-1091.

51. Marre M, Shaw J, Brandle M, Bebakar WM, Kamaruddin NA, Strand J, et al. Liraglutide, a once-daily human GLP-1 analogue, added to a sulphonylurea over 26 weeks produces greater improvements in glycaemic and weight control compared with adding rosiglitazone or placebo in subjects with type 2 diabetes (LEAD-1 SU). Diabet Med. 2009;26:268-278.

52. Nauck M, Frid A, Hermansen K, Shah NS, Tankova T, Mitha IH, et al. Efficacy and safety comparison of liraglutide, glimepiride, and placebo, all in combination with metformin, in type 2 diabetes: the LEAD (liraglutide effect and action in diabetes)-2 study. Diabetes Care. 2009;32:84-90.

53. Russell-Jones D, Vaag A, Schmitz O, Sethi BK, Lalic $\mathrm{N}$, Antic S, et al. Liraglutide vs insulin glargine and placebo in combination with metformin and sulfonylurea therapy in type 2 diabetes mellitus (LEAD-5 met+SU): a randomised controlled trial. Diabetologia. 2009;52:2046-2055.

54. Zinman B, Gerich J, Buse JB, Lewin A, Schwartz S, Raskin $\mathrm{P}$, et al. Efficacy and safety of the human glucagon-like peptide-1 analog liraglutide in combination with metformin and thiazolidinedione in patients with type 2 diabetes (LEAD-4 Met+TZD). Diabetes Care. 2009;32:1224-1230. 